\title{
ACRL issues for the 80s and 90s
}

\section{$A C R L$ 's two presidential candidates offer their views on the Association's future.}

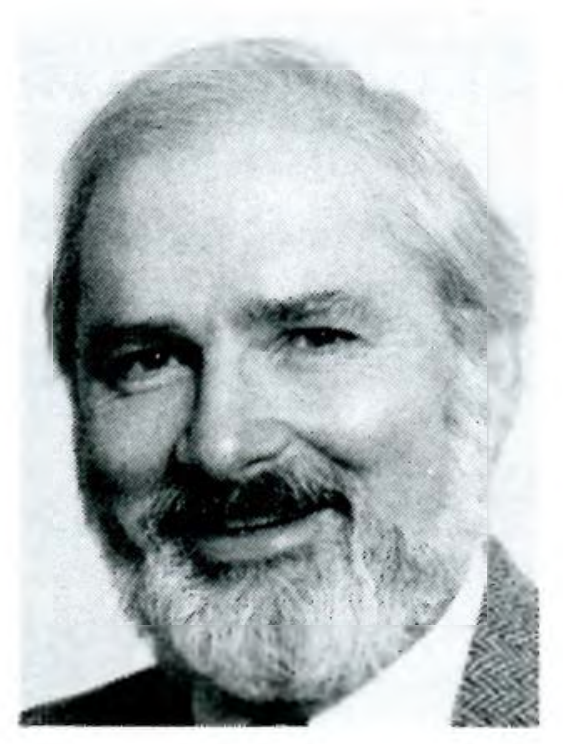

William A. Moffett

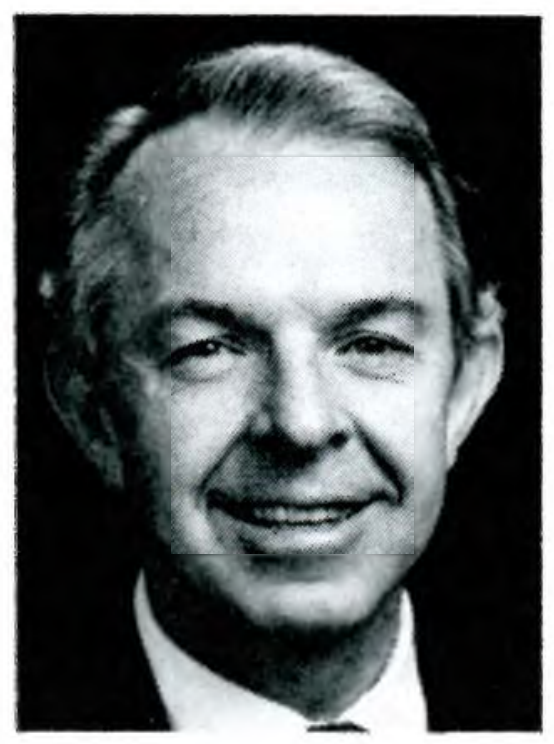

David B. Walch

$\mathbf{T}$ his presentation of statements from ACRL's candidates for Vice-President/President-Elect is an information service for ACRL members. Many of the issues and concerns facing ACRL are discussed informally at meetings, but this does not provide a national forum available to all members. These statements provide the basis for an informed choice when you receive your ballot next month.

\section{William A. Moffett:}

The candidate elected this spring will serve as President in the 1989-90 year.

Each year at this time ACRL elections can be counted on to produce some stocktaking on this page (sometimes a little hackneyed), characteristically looking forward to challenges looming ahead; inevitably looking backward in hopes of taking some encouragement from evidence of past achievement.

The impulse to indulge in such an exercise seems heightened when the election-or the term of office-coincides with a notable milestone: observing the hundredth anniversary of the beginnings of an academic library section in ALA, beginning a

second half-century as ALA's premier division, or even just entering a new decade. This time, when all three more or less coincide, the process is inescapable. Besides, for me the decision to accept the nomination hinged on just such a review.

Looking back. A wag once dismissed a midwinter assemblage of dedicated ACRL activists as "people who have embraced gridlock as a way of life."

But when one looks over the record, and especially that of the past ten years since Evan Farber, Le Moyne Anderson, and their colleagues on the Board began targeting and engaging the "issues for the 80s" (a record fully chronicled in the annual reports of successive Presidents and Executive Directors that have appeared regularly in this journal), one finds both remarkable movement and substantial accomplishment to celebrate.

-ACRL has worked out a more congenial relationship with ALA.

-We've not only survived a fiscal crisis, but emerged with a sounder and more manageable financial structure.

- Continuous tinkering with constitution and bylaws has in fact resulted in a leaner, more efficient Board and more responsive machinery for governance and communication.

- Sustained effort by a succession of leaders has produced a model apparatus for strategic planning and evaluation.

-We've seen steady development of an exceptionally supportive headquarters staff.

- A much needed program of continuing education has been created and gained acceptance.

- There have been admirable achievements in our publications program - the success of the new journal, Rare Books and Manuscripts Librarianship, being the most notable recent example.

- There has been the splendid series of well- 
arranged national conferences, along with the surge of new interest they've provoked; membership has climbed within this period from below nine to nearly ten thousand.

- There have been stirrings in the grassroots; the number of chapters will have almost doubled by the end of the decade, and the enthusiasm and vitality of Chapters Council is at an all-time high.

And ahead. For all that progress, however, none of us should be surprised if many of the "issues for the 80 s" reappear in subsequent pages as "issues for the 90s."

Our relationship with ALA is inherently problematic, and judging from an anxious meeting in San Antonio in which indignant Division heads protested their not having been consulted before new ALA costs were imposed, we still need a skillful and combative advocate to represent us. (Incidentally, it might help if the ACRL membership would bestir itself to use its electoral strength to claim a commensurate share of Council seatssomething we've never done.)

Our recently established fiscal strength can hardly be taken for granted, especially as we respond to a very real need to allocate support for new initiatives being developed by sections and chapters.

We've got to get the bugs out of the Strategic Plan. Although "strategic planning" is undoubtedly the busiest buzzword of the year in higher education, our own is no fad; it is eminently reasonable and well considered; it is also breathtaking in its comprehensiveness. There is some concern that we've become absorbed in perpetual planning; some groups at Midwinter were beginning to grumble that so much time was being devoted to planning and evaluation there was going to be little left in which to actually $d o$ anything. The Strategic Plan, however, is not an end in itself; a model for decision-making is, after all, still just that, a model. Ultimately it is about values, not process.

There is some apprehension that our leaner, more efficient governance structure reinforces still more powerfully the traditional bias towards the concerns of librarians identified with larger institutions. But can still more tinkering be counted on to offset it? Surely the chief corrective must be greater assertiveness by those associated with smaller institutions, and greater responsiveness by those in positions of leadership.

Some older issues are likely to reappear, of course, because we never managed to address them adequately in the past. Despite at least a decade of panting and wing-flapping, for example, the much discussed initiative to achieve visibility in and respect from other professional bodies is still struggling to get off the ground. I myself presented a session for ACRL in the 1981 meeting of the American Council of Education; it was our first such effort, and very nearly the last. (I trust it wasn't something I said.) In 1988 we find ourselves once again trying to determine which associations in higher educa- tion ACRL should establish ongoing liaisons with. It's square one.

And we've still not come to grips with that venerable conundrum: how do we convert resource sharing from a lofty concept to which most of us pay lip service into a workable reality we can support in practice? Will our changing environment, eroded by economic decline and reshaped by new technology, make this problem more, or less intractable?

Meanwhile, some wholly new issues are coming our way, or at least some rather old problems with a new sense of urgency. Forecasters are predicting a serious shortage of academic librarians within the next decade. That may gladden the hearts of library school administrators, but hardly the rest of us. Where are our new librarians coming from? And what can ACRL do, if anything, to promote recruitment and improve the quality of the education they're likely to get?

In short, there's no shortage of challenges. It is a question of how to engage them productively.

Not surprisingly, ACRL has often shown greater readiness to address procedural and constitutional problems that arise from the internal workings of the organization than either the professional issues that confront the average librarian or the needs of the clientele the academic librarian exists to serve. Ultimately, it is in dealing with these latter two goals that our success or failure will be judged.

And it is precisely here that the Strategic Plan may be most useful, for it holds out both-"the total professional development of academic and research librarians" and "enhancing the capability of our libraries to serve the needs of users"-as the very first of our objectives.

Can elected officials make a difference? But can an individual president, even with a three-year term on the Board, really make a difference in how we fulfill the plan?

One cannot accept an invitation to be a candidate-an honor, to be sure, but potentially and even more importantly, a substantial commitment of effort and institutional resourceswithout convincing oneself that the answer has to be yes.

One has only to think of some recent presidents who unquestionably made a difference, persons who could be held up as role models for any prospective candidate:

- Le Moyne Anderson, who I remember primarily for being a tenacious and articulate advocate of ACRL interests.

- Penny Abell, for her good-humored encouragement of others.

- David Weber, for his clearheaded and farsighted establishment of long-range planning.

- Carla Stoffle, for a sense of vision and a grasp of how to get things done that is still causing things to get done years later; whose exceptional presidential report (C\&RL News, July/August 1983), with its eloquent statement of purpose, should be required reading for all ACRL officers. 
-Evan Farber, for his ability to listen, his wise counsel, and for demonstrating conclusively that effective leaders are to be found in small as well as large institutions.

And from my own span of active involvement I know full well any such list needn't be confined to presidents. One can think of many examples of individuals who've made a difference-in the people who've put together our national programs, who edit our publications, who steer committees, who sustain the life of a section.

But my very awareness of and appreciation for those individuals and their contributions give way to a quandary. It's not easy to express in a few words, but let me try.

Extending the circle. Those who already serve on committees and participate regularly in other ways on the national level must acknowledge that the Association must look very different to members who infrequently attend the major conferences, as well as to the vast host of professional academic librarians who are not members at all (and there are far more of them than there are members), but whose interests we say we are attempting to serve.

Let me admit to an evangelical impulse. I have always been concerned about the people "outside" - those who do not join, who've dropped out or been turned off, who aren't attracted or simply can't afford to come to our national meetings. We've had some success in the College Libraries Section recently in reviving interest and bringing new people in. I'd like to see that happen across the board.

The series of national conferences that started in Boston ten years ago and continues in Cincinnati next year has obviously helped to some extent; we've observed the rise in membership and the stimulation of professional discourse directly attributable to those meetings. But surely more can be done.

The President-Elect can make a difference by the people he or she puts on the Appointments Committee and by the kind of mandate they are given. We can insure that we don't perpetuate an "old persons network," but instead encourage fresh participation and provide new opportunities for growth and for potential leadership.

But such affirmative action, as well as the proliferation of committees and task forces, and the extension of committees by internships-helpful as all that is in increasing opportunities for participation-still will not address the question of how to involve the many thousands of academic librarians in the United States and Canada for whom regular attendance at Midwinter meetings is just not an option.

One very promising initiative, and the one I'd want to promote if elected, is to give greater support to activities at the chapter level. They are increasingly seen as providing a more gratifying opportunity for interaction, for getting to know one's counterparts, for sharing ideas, experiences, and information, for meaningful workshops, for developing new cooperative ventures, for starting things that can be sustained after the meeting is over. The challenge, of course, is not merely one of encouraging grassroots activity, but of integrating it within the Association, of insuring that it genuinely invigorates, not dissipates our effort to fulfill the mission we've set out for ourselves.

I want ACRL to make a difference in the quality of academic librarianship and the service we render to higher education. I believe that elected officeholders, part-time and fleeting though their terms may be, can make a difference. That's why I accepted the nomination.

William A. Moffett is director of libraries at Oberlin College, Ohio.

\section{David B. Walch:}

In preparation for this activity and also as an effort to be as well prepared as possible as an ACRL Presidential candidate, I have again reviewed with keen interest the activities and foci of the Association during the decade of the 80s. The review reaffirms the fact that ACRL is a dynamic, healthy, organization that is striving to meet the needs of its members. For example:

- Since 1985 membership has grown from 8,500 to close to 10,000 .

- Since 1980 the budget has improved to a point where ACRL now has a six-month reserve fund.

- Since 1980 publications (identified as membership's \# 1 priority) continue to grow in number and quality.

- Since 1980 the number of chapters has grown from a very few to 39 .

- Since 1980 the baton of the Executive Director has been successfully passed from Julie Virgo to JoAn Segal, and the services rendered by that important office and staff continue to be strong and well-directed. Elected leadership has likewise been affective and perceptive.

- Since 1979 three successful ACRL national conferences have been held and attracted large numbers of participants.

- Since 1980 a very capable Strategic Planning Task Force has developed an ACRL Strategic Plan that provides a clear sense of mission, a strong set of goals with specific objectives and strategies.

One might ask what can an ACRL President do in a relatively brief tenure that would influence the direction of an organization that already appears to be making good progress. Obviously there are a number of responsibilities assigned to that position that influence the organization, e.g., recommending appointments to a variety of committees, chairing the ACRL Conference Program Planning Committee, reviewing budget requests and expenditures, etc. Beyond this there are other, somewhat obvious, but certainly important matters on which to focus, and as a candidate for Vice- 
President/President-Elect of ACRL, I want you to know where I stand in regard to at least four areas that I believe deserve emphasis and attention.

1. The Strategic Plan. As a candidate I see the Strategic Plan approved by the ACRL Board on July 1,1986 , as a critically important document that reflects where the grass-roots membership of ACRL wants the Association to go. I make a commitment as a candidate to use whatever influence, whatever energy, whatever time is required to see the plan realized. I would also note that the plan is a five-year plan with the fifth year being 1990 , i.e., the same year that this year's candidate will be in office. Hence the need to work carefully with the Planning and Budget Committees and other members of the Association toward the continued development of plans and strategy.

2. Membership Involvement. As a candidate I see the need to involve as many members of the Association as possible. This year the membership exceeds 10,000 . Serving this membership are 14 Sections, 39 Chapters, 48 Committees, 14 Discussion Groups, and a number of Task Forces. It is estimated that those involved in leadership positions number approximately 350 , or only $3.5 \%$. I believe it is appropriate to review the opportunities provided for membership to participate. Are we tapping the vast pool of new and young expertise available or are we relying too heavily on those whom we know by virtue of their previous committee service? Certainly, the intern process has been helpful, but in addition I should like to see encouragement extended and opportunities provided to the newer members of the Association and to further encourage that appropriate balance between university, college and community college appointees be made.

3. Continuing Education. As a candidate I see a need to continue the emphasis placed on continuing education opportunities. The 1984 ACRL survey distributed to a random sample of $600 \mathrm{mem}$ bers reflected a major need for continuing education. Of the ten items listed, it was ranked a close second to that of publications. There are a variety of ways continuing education occurs within the Association, including attendance at the annual convention, the national conferences, and pre-conference workshops. It is the chapters, however, that enable the Association to reach out to the grassroots level of both members and potential members. This link must continue to be nourished. Continuing education opportunities that have been heavily based on courses and meetings offered at ALA Annual and Midwinter Conferences need to be extended to a series of learning opportunities in different formats, and different locations, and at different times.

4. Consumerism. As a candidate I see a critical need for academic libraries to pull together and unitedly address the rapid escalation of journal subscription prices. As one noted national library figure observed, "libraries have become hostages to those publishers who have priced their journals beyond a fair profit." Journal prices continue to increase at a much greater rate than other consumer goods. For example, the 1986 periodical subscription price rose $8.9 \%$ as compared to only a $1.9 \%$ increase in the Consumer Price Index. This problem has been further exacerbated with the declining dollar. Though this concern is one that relates more to the institution in which we work than the organization in which we hold membership, it is a problem that is exacting a heavy toll on the quality of our academic libraries. A basic working principle of this Association is that it "speaks for the academic library profession on issues of importance to...academic...libraries." Given the fact that there are nearly 1,000 institutional, i.e. library, memberships in ACRL, it seems appropriate for the organization to vigorously address this matter.

Obviously there are many other areas of concern that deserve attention beyond the four upon which I have focused. Since being nominated I have at. tempted to contact a number of ACRL members and inquire after their specific concerns. A variety have been broached including such matters as the development of output or performance measures, preservation, the role of rare book and special collection libraries in times of fiscal constraint, and administrative relationships between libraries and campus computing organizations. Many of these issues are being reviewed by the various committees and organized groups within ACRL.

In 1968 Lawrence Clark Powell reflected on his life as a library organization man. He noted that professional organizations have a common life cycle. They begin, he stated, "as small clusters of gregarious, dedicated individuals, gradually grow, proliferate, subdivide, and depersonalize, and become powerful, useful, necessary - and tedious in their involved proceedings." Of the Association of American Library Schools he said: "I can say nothing either for it or against it. It is a nonentity." Of the Special Libraries Association he said: "Though a member I found their publications and meetings intellectually arid and overly technical." Of the Association of Research Libraries, where he served as an executive board member and also as chairman, he said, "The proceedings never engaged me deeply, except for some brushes I had with Keyes Metcalf..." Though he said nothing specifically about ACRL he did say, "I was a good organization man. Although critical of professional groups, I never broke with them. I made myself an inside nuisance to some and a conscience voice to others."

As a candidate I would welcome that opportunity of becoming, if not an inside nuisance, at least a voice of conscience for the membership of this esteemed Association.

David B. Walch is director of libraries at California Polytechnic State University, San Luis Obispo. 


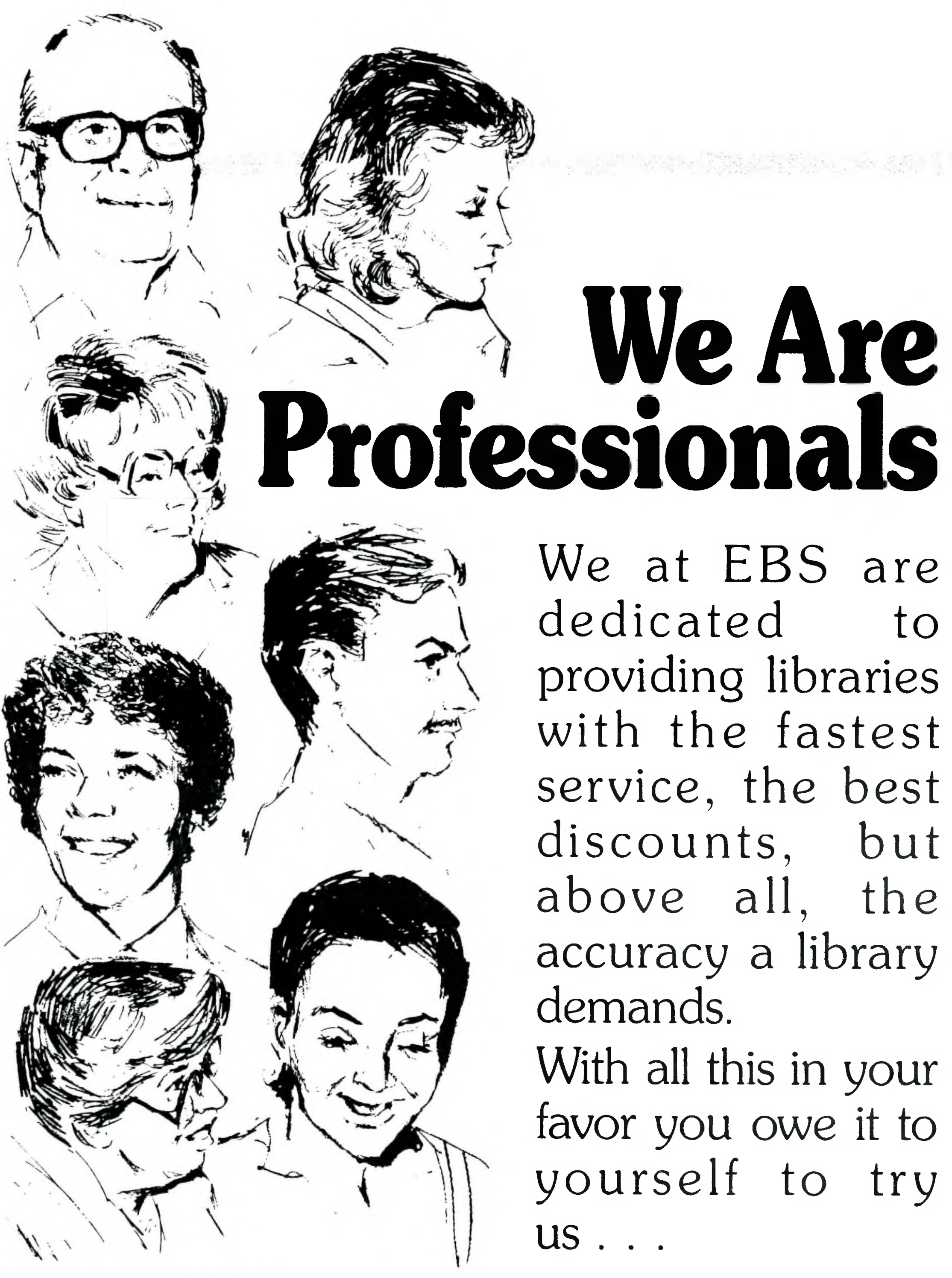

|III||IIIIIII

 E.B.S. BOOK SERVICE THE BEST CHOICE. ESTABLISHED 1949 